\title{
A contribuição das tecnologias de informação e comunicação em espaços não formais de ensino: estudo de caso na floresta nacional de Piraí do Sul, PR
}

\section{The contribution of information and} communication technologies in non-formal teaching environments: a case study in the national forest of Piraí do Sul, PR, Brazil

\section{La contribución de las tecnologías de información y comunicación en espacio no formal de ensino: estudio de caso en la floresta nacional de Piraí do Sul, PR, Brasil}

\author{
(iD) Lia Maris Orth Ritter Antiqueira \\ Universidade Tecnológica Federal do Paraná - Ponta Grossa - Paraná - Brasil \\ liaantiqueira@utfpr.edu.br \\ (iD) Rubia Freitas Pinheiro \\ Universidade Tecnológica Federal do Paraná - Ponta Grossa - Paraná - Brasil \\ rubiapinheiro.freitas@gmail.com
(D) Romeu Miqueias Szimoski Universidade Tecnológica Federal do Paraná - Ponta Grossa - Paraná - Brasil rmszmoski@utfpr.edu.br

Resumo: Este trabalho aborda a importância dos espaços não formais de ensino e das Tecnologias de Informação e Comunicação como estratégias para ensino de Educação Ambiental. Apresenta-se um proje- 
to inovador de implementação de QR Codes em trilhas ecológicas em uma Unidade de Conservação no estado do Paraná (Floresta Nacional de Piraí do Sul) e as possibilidades de realização de saídas de campo ou aulas-passeio, que são recomendadas desde a Escola Moderna de Freinet, mas que ganham força na atualidade baseadas na premissa de necessidade de resgate da conexão do ser humano com a natureza.

Palavras-chave: Educação Ambiental. Espaço Não Formal. Ensino de Ciências. Aula- Passeio. Unidade de Conservação.

Abstract: This work addresses the importance of non-formal educational spaces and Information and Communication Technologies as strategies to teaching Environmental Education. We present an innovative project to implement QR Codes in ecological trails in a Conservation Unit in the state of Paraná, Brazil (National Forest of Piraí do Sul) as well as the possibilities of conducting field trips or walking lessons, which have been recommended since the Freinet Modern School and are becoming more important nowadays based on the need to restore the connection between humans and nature.

Keywords: Environmental Education. Non-Formal Space. Science Teaching. Walking Lesson. Conservation Unit.

Resumen: Este trabajo aborda la importancia de los espacios no formales de enseñanza y de las Tecnologías de Información y Comunicación como estrategia para la enseñanza de la Educación Ambiental. Se presenta un proyecto innovador de implementación de QR Codes en senderos ecológicos en una Unidad de Conservación en el estado de Paraná (Bosque Nacional de Piraí do Sul) y las posibilidades de realización de salidas de campo o clases de paseo, que se recomiendan desde la Escuela Moderna de Freinet pero que ganan fuerza en la actualidad basadas en la premisa de necesidad de rescate de la conexión del ser humano con la naturaleza.

Palabras clave: Educación Ambiental. Espacio No Formal. Enseñanza de Ciencias. Aula Paseo. Unidad de Conservación. 
A contribuição das tecnologias de informação e comunicação em espaços... Lia Maris Orth Ritter Antiqueira.Rubia Freitas Pinheiro• Romeu Miqueias Szimoski

\section{Introdução}

Muito se discute na atualidade sobre a importância de modificar as metodologias tradicionais de ensino para que a aprendizagem deixe de ser vista como um processo de memorização de termos técnicos e passe a se tornar atrativa, fazendo parte da vida dos estudantes.

No caso específico do ensino de Ciências, esta premissa engloba duas questões importantes que podem servir como aliadas neste processo: (i) a conexão do ser humano com a natureza (que se inicia por meio da educação ambiental desde os primeiros anos de vida) e (ii) o uso de ambientes não formais como ferramenta de ensino.

Parte-se deste contexto ao considerar que quando os estudantes são participantes ativos e integrados em um processo que tenha para eles real significado, o ensino deixa de ser imperativo e informativo, passando a ser discutível e de fácil compreensão, permitindo aproximação eficaz e incorporação do conhecimento para a vida.

Propõe-se discutir aqui estratégias interdisciplinares que possam ser realizadas em ambientes não formais (Unidades de Conservação), conciliando o uso de Tecnologias de Informação e Comunicação (TICS) com a finalidade de promover o ensino, ancorando-se na metodologia de aula passeio proposta por Célestin Freinet.

\section{Espaços não formais de ensino e as aulas-passeio de Freinet}

Os espaços não formais de ensino podem ser definidos como locais diferentes da sala de aula onde é possível adotar práticas educativas e promover a aprendizagem. 
A contribuição das tecnologias de informação e comunicação em espaços... Lia Maris Orth Ritter Antiqueira•Rubia Freitas Pinheiro• Romeu Miqueias Szimoski

Jacobucci (2008) organiza os espaços não formais em duas categorias: (i) ambientes que possuem uma equipe especializada na estrutura e componentes do lugar (como museus, parques ambientais, ambientes de pesquisa científica e de preservação), e (ii) espaços flexíveis, em que pode ocorrer o lazer e o ensino (como lagos, campos de futebol, praia, entre outros).

É importante salientar que a utilização destes espaços como ambiente de ensino possibilita ao estudante um crescimento pessoal além de acadêmico, tanto que na atualidade há muitos autores que defendem o ensino "fora da sala de aula", como Pivelli (2006), ao afirmar que o ensino abrange todas as possibilidades educativas proporcionadas ao longo da vida de um indivíduo, constituindo um processo permanente e não organizado.

Vieira, Bianconi e Dias (2005) definem o aprendizado como o desenvolvimento da essência do indivíduo, compreendendo o conhecimento informal (popular), o formal (escola) e os espaços não formais, que são todos os outros ambientes que criam e/ou possibilitam a interação do aluno com o conteúdo estudado em sala de aula, saindo do ensino tradicional fixado no uso do quadro negro e memorização.

Sobre este aspecto, Jacobucci (2008) aponta que, embora haja um senso comum que a educação não formal é diferente da formal (por utilizar ferramentas didáticas diversificadas e atrativas), isto nem sempre é verdade.

Desse modo, constata-se que não é o ambiente que vai definir se o tipo de aprendizagem é formal ou informal, pois uma aula de campo pode ser extremamente tradicional, ao mesmo tempo que uma atividade em sala de aula pode ser totalmente dinâmica e diversificada (JACOBUCCI, 2008).

Os espaços não formais se apresentam como possibilidades para que o conhecimento seja construído, desde que o professor planeje uma interação que proporcione tais resultados em benefício dos alunos. Shimada e Terán (2014) afirmam que, neste caso, os benefícios incluirão a compreensão dos conteúdos trabalhados 
A contribuição das tecnologias de informação e comunicação em espaços... Lia Maris Orth Ritter Antiqueira•Rubia Freitas Pinheiro• Romeu Miqueias Szimoski

em sala, tornando o aluno capaz de assimilar concretamente o novo aprendizado.

Ao discutir possibilidades de uso dos espaços não formais em atividades de campo, Pinheiro e Antiqueira (2019) resgatam na literatura Bizerril e Faria (2003), que defendem o uso da informação cientifica à experiência direta: o professor deixa os estudantes confortáveis para argumentar, estreitando laços com a natureza, colaborando na construção de valores e tornando-se cidadãos críticos e conscientes.

Almeida (2000) afirma que a relação entre o meio ambiente e a educação visando a cidadania assume um papel cada vez mais desafiador, demandando uma nova forma de encarar a relação do homem com a natureza. Para a autora, esta relação se baseia em uma nova forma de ver o mundo e os homens.

Estas preocupações já faziam parte dos estudos de Célestin Freinet, pedagogo francês que ficou conhecido pelo movimento da Escola Moderna na década de 1920, em que defendeu a educação focada na liberdade e criticidade do aluno, propiciando a ele autonomia na construção do conhecimento e fuga do tradicionalismo.

Uma das abordagens utilizadas por Freinet, denominada de aula-passeio, foi desenvolvida como alternativa para valorizar o interesse que os alunos apresentavam por atividades diferenciadas, assim como a curiosidade, que era um fator muito evidente. Segundo o autor, ao retornar para sala de aula após a atividade, era possível observar a animação e curiosidade que os alunos apresentavam ao associar o conteúdo científico com seu cotidiano.

Com sua metodologia, Freinet (1975) propiciava uma relação dos alunos com o conhecimento, de forma que trabalhavam o conteúdo com materiais produzidos por eles mesmos, como, por exemplo, textos, desenhos, jornais entre outros, produzindo, dessa forma, a compreensão dos conceitos e não somente um conhecimento passageiro.

Assim, é notável que há vantagens em trabalhar com essa dinâmica, pois ela proporciona um contato direto com o conheci- 
A contribuição das tecnologias de informação e comunicação em espaços... Lia Maris Orth Ritter Antiqueira•Rubia Freitas Pinheiro• Romeu Miqueias Szimoski

mento e o processo de compreender o fenômeno, que se associa a um conceito. Além disso, melhora a relação professor-aluno, que se torna flexível e próxima em um ambiente diferente da sala de aula, deixando ambos mais confortáveis.

Conforme Sampaio (1996), os ganhos para os alunos neste tipo de atividade incluem desde aprender a partir do mundo real (satisfazendo a curiosidade, desenvolvendo espírito crítico e a capacidade de se adaptar à diversas situações e resolver pequenos problemas), ajudar os outros, desencadear respostas em um contexto novo, até nutrir o imaginário e deixar de ser um consumidor para se tornar um construtor.

Quando bem planejada e utilizada, esta metodologia é eficiente no ensino, visto que congrega diversas fontes de conhecimento em um ambiente familiar, possibilitando autonomia e a construção do conhecimento. Elias (1996, p. 59) afirma que, para tanto, cabe ao educador criar condições de trabalho e ação, "aproximando a criança da realidade para que possa desvelá-la e criticá-la para em seguida poder reconstrui-la e reinventá-la, transcendendo assim a simples esfera da apreensão".

Portanto, para elaboração de uma aula-passeio, é fundamental que o professor esteja aberto a mudanças em sua programação, pois o ambiente pode ocasionar caminhos de conhecimento diferentes. Além disso, podem surgir perguntas, curiosidades e comentários e é preciso estar atento para conduzir a dinâmica.

Freinet (1975) frisa a necessidade de registrar todas as falas dos alunos de alguma forma, para posteriormente em sala de aula conseguir mesclar as observações com o conteúdo. Devido as possibilidades tecnológicas disponíveis (gravadores de voz, de imagem, câmeras fotográficas, tablets e mesmo os tradicionais blocos de anotação), não há dificuldades em atender este pressuposto para organizar a atividade.

Com planejamento e administração a saída de campo pode ser uma ferramenta valiosa para trabalhar os conteúdos do plano curricular associando com a realidade. No entanto, Sampaio (1996) 
A contribuição das tecnologias de informação e comunicação em espaços... Lia Maris Orth Ritter Antiqueira.Rubia Freitas Pinheiro• Romeu Miqueias Szimoski

alerta que é necessário esforço para que essa comunicação sensibilize a todos (educadores e alunos), provando que este tipo de atividade não é perda de tempo e nem atrapalha o desenvolvimento do currículo escolar, mas, ao contrário, enriquece os aspectos social, intelectual e afetivo.

As Tecnologias de Informação e Comunicação no ensino

As TICs são uma realidade no cotidiano atual. Pinheiro e Antiqueira (2019) analisam o fácil acesso e entendimento que os jovens adquirem sob os recursos tecnológicos como computadores, celulares, internet, games e câmeras. As autoras afirmam que na maioria das vezes os comandos dos equipamentos são intuitivos e com alguns minutos de contato é possível dominar o seu uso.

O conjunto das TICs pode ser utilizado de forma integrada como apoio ao professor para despertar o interesse dos estudantes, pois estão ligadas tão estreitamente às pessoas que já são consideradas como uma extensão do ser humano.

No entanto, ainda há divergências sobre o uso de novas tecnologias em sala de aula. Para Santana (2015), a escola ainda não faz uso de todo o potencial que deveria. Continua baseando as aulas com estratégias que não estimulam a reflexão e a criticidade do aluno, reproduzindo automaticamente conteúdos que muitas vezes estão desatualizados. E este cenário muitas vezes acontece em instituições que possuem recursos como laboratórios de informática equipados.

Em contraponto, Augusto (2014) aponta que muitos professores fazem uso destes recursos e acreditam que são um passo importante no processo de ensino-aprendizagem.

Descrita na nova Base Nacional Comum Curricular (BNCC), a utilização da tecnologia como apoio ao ensino é importante para um melhor processo de ensino- aprendizagem. Constam dentre as competências da BNCC, "analisar, compreender e explicar características, fenômenos e processos relativos ao mundo natural, social e tecnológico, como também as relações que se estabelecem entre eles" (BRASIL, 2017). 
A contribuição das tecnologias de informação e comunicação em espaços... Lia Maris Orth Ritter Antiqueira•Rubia Freitas Pinheiro• Romeu Miqueias Szimoski

Nesse contexto, o professor pode adequar sua metodologia de ensino e incluir as TICS como parte do processo de ensino-aprendizagem, desafiando o aluno a buscar o conhecimento. Mas para obter sucesso com esta abordagem é necessário que o professor esteja preparado para ser o mediador entre as tecnologias e o conhecimento, tendo sempre em mente que deve antes de tudo repensar sua conduta metodológica para usar as TICs a favor do ensino.

De acordo com Vasconcelos e Oliveira (2017, p. 121), uma das dificuldades é conciliar a variedade de fontes de acesso com o aprofundamento da sua compreensão: "é necessário que os conteúdos tenham sentido para o aluno e que as informações possam ser acessadas nos mais diferentes lugares e se transformar em conhecimentos".

Assim, o professor precisa apresentar caminhos para o aluno construir o conhecimento. Conforme afirma Souza (2012, p. 58), “a ideia é dar aos estudantes ferramentas alternativas para apoiar e potencializar a construção de conhecimento e facilitar o trabalho colaborativo em uma aula".

Esse fato se confirma com as estratégias utilizadas por Freinet na década de 1920, buscando desenvolver a criticidade do aluno, tornando-o sujeito do processo e o professor atuando como mediador e facilitador. Na época, a construção do conhecimento pelo aluno se dava por meio da estratégia de produção do "Jornal Escola".

Embora defendidos por Freinet há quase um século, esses métodos podem ser empregados em qualquer época, desde que se sejam utilizadas em sala aula as estratégias que façam parte da realidade atual, inserindo os aspectos contemporâneos para a escola de forma a modernizar a sala de aula.

Assim, se houver a possibilidade do professor utilizar TICs em suas aulas, sugere-se que o faça, pois, para Kayser e Montes (2017), a tecnologia está cada vez mais presente no dia a dia de todos e quando bem direcionada é capaz de instigar todos os atributos 
A contribuição das tecnologias de informação e comunicação em espaços... Lia Maris Orth Ritter Antiqueira.Rubia Freitas Pinheiro• Romeu Miqueias Szimoski

necessários para um processo de ensino-aprendizagem, explorando a ligação do conhecimento com a tecnologia, assim deixando o conteúdo amplo e proporcionando o interesse do aluno.

As TICs também são defendidas por Ribas, Silva e Galvão (2015). Para os autores, se os professores estiverem preparados e tiverem autonomia para explorar o universo das tecnologias, poderão oportunizar aos alunos o interesse necessário, trazendo desafios para trabalhar o cognitivo e aprofundar diversos conteúdos, possibilitando situações que desenvolvam a criticidade, entre demais outros benefícios.

\section{Estudo de caso na Floresta Nacional de Piraí do Sul - PR}

As Unidades de Conservação (UC) são áreas protegidas por legislação, cujo objetivo principal é a preservação de ambientes naturais e seus componentes, de acordo com a necessidade de cada região.

Dentre as categorias de UC, há áreas de domínio público e propriedades particulares que contém vegetação nativa. Um exemplo são as Florestas Nacionais (FLONA), que dentre as prerrogativas de uso (respeitando o Plano de Manejo da unidade), permitem a visita pública, com incentivo à pesquisa e à Educação Ambiental.

Rodrigues e Colesanti (2015) pontuam que além das funções iniciais de conservação, lazer e contemplação, as UC incorporam com frequência funções didáticas que motivam a inserção de programas de Educação Ambiental em seus Planos de Manejo e atividades com os visitantes.

Para as autoras, estas atividades acontecem por meio de foIhetos informativos, vídeos, sites, palestras, cursos e visitas monitoradas. No entanto, afirmam que os materiais produzidos para estas finalidades em sua grande parte não refletem os objetivos do Programa Nacional de Educação Ambiental (BRASIL, 2005), 
A contribuição das tecnologias de informação e comunicação em espaços... Lia Maris Orth Ritter Antiqueira•Rubia Freitas Pinheiro• Romeu Miqueias Szimoski

possuindo, geralmente, uma ótica disciplinar, segmentada e meramente informativa (RODRIGUES; COLESANTI, 2015).

Almeida (2008) afirma que o meio ambiente apresentado como tema transversal nos Parâmetros Curriculares Nacionais (BRASIL, 1998) tem por função promover uma visão ampla dos elementos naturais e construídos e dos aspectos a eles relacionados. Ou seja: pretende-se que o aluno relacione situações da vida real e adote posturas mais críticas, de forma a exercer cidadania e desenvolver uma consciência ambiental.

Assim, as UC podem ser utilizadas como espaços não formais para o ensino, funcionando como recursos didáticos diferenciados do ambiente escolar, onde o aluno pode relacionar o conteúdo de sala de aula com o contexto e com a própria vida, facilitando o aprendizado. Além disso, possibilitam a realização de aulas práticas interdisciplinares com abordagens de diferentes aspectos das Ciências.

Então, partindo-se do pressuposto que os materiais utilizados em Educação Ambiental nas UC devam ir além da simples informação, enfocando temáticas interdisciplinares e problematização de questões socioambientais, conforme explicitam Rodrigues e Colesanti (2015), é necessário pensar em materiais criativos que fomentem o tema de forma atual, divertida e interessante.

O Sistema Nacional de Unidades de Conservação (SNUC, 2000) destaca em seus objetivos a necessidade de integrar as UC ao ensino, sugerindo atividades com enfoque em educação ambiental, para formar cidadãos conscientes em relação à natureza, integrando o conhecimento da sala de aula.

Para que estas premissas sejam alcançadas, Rodrigues e Colesanti (2015) consideram a possibilidade de uso de novas TICS na divulgação de informações textuais, imagens, músicas, fotografias, filmes e mapas, de forma a apreender a complexidade ambiental e a perspectiva interdisciplinar, valorizando também a percepção da comunidade. 
A contribuição das tecnologias de informação e comunicação em espaços... Lia Maris Orth Ritter Antiqueira.Rubia Freitas Pinheiro• Romeu Miqueias Szimoski

Desta forma, as UC acabam por se tornar importantes espaços de ensino, pois possibilitam que a realidade local esteja presente na educação de forma geral. Conforme salientam Costa, Costa e Mello (2005), a Educação Ambiental está intrinsecamente ligada à mediação de um conhecimento científico vinculado à realidade cotidiana dos alunos, que os levarão a ações concretas, iniciadoras de uma mudança comportamental individual e coletiva.

Cabe também ressaltar o aspecto da interdisciplinaridade que pode ser explorado nas UC enquanto espaços não formais de ensino, de forma a superar o impasse de organização dos conteúdos. Como relatado na Base Nacional Comum Curricular (BNCC), é importante adotar estratégias dinâmicas, interativas e colaborativas nos processos de ensino- aprendizagem (BRASIL, 2017).

Nas possibilidades de atividades a serem desenvolvidas em UC, há elementos da Geografia local que podem ser discutidos junto aos aspectos de Ciências, sejam relacionados às características de solo, hidrografia, paisagem ou antropismo. Afinal, tanto quanto as Ciências, a Geografia é um campo eclético. Moreira (2010) vai adiante neste raciocínio e defende que ao estudar a relação homem-meio, a Geografia se torna um campo no qual se mesclam todas as Ciências.

Além destas claras correlações, a perspectiva interdisciplinar pode abranger elementos de História, Matemática, Língua Portuguesa, Artes, dentre outras disciplinas que podem ser organizadas na forma de atividades conjuntas.

\section{Área de Estudo}

A Floresta Nacional de Piraí do Sul é uma unidade de conservação com área de 150,61 hectares, gerida pelo Instituto Chico Mendes de Conservação da Biodiversidade (ICMBio). Localiza-se a 6 km da sede municipal de Piraí do Sul, Paraná, no Sul do Brasil (Figura 1). 
A contribuição das tecnologias de informação e comunicação em espaços... Lia Maris Orth Ritter Antiqueira•Rubia Freitas Pinheiro• Romeu Miqueias Szimoski

Foi criada por decreto (sem número) de 02 de junho de 2004, com o objetivo de promover o manejo de uso múltiplo dos recursos florestais e a pesquisa científica, com ênfase em métodos para exploração sustentável das florestas nativas.

Figura 1 - Mapa de localização da Flona de Piraí do Sul LOCALIZACÃO DA FLORESTA NACIONAL DE PIRAÍ DO SUL

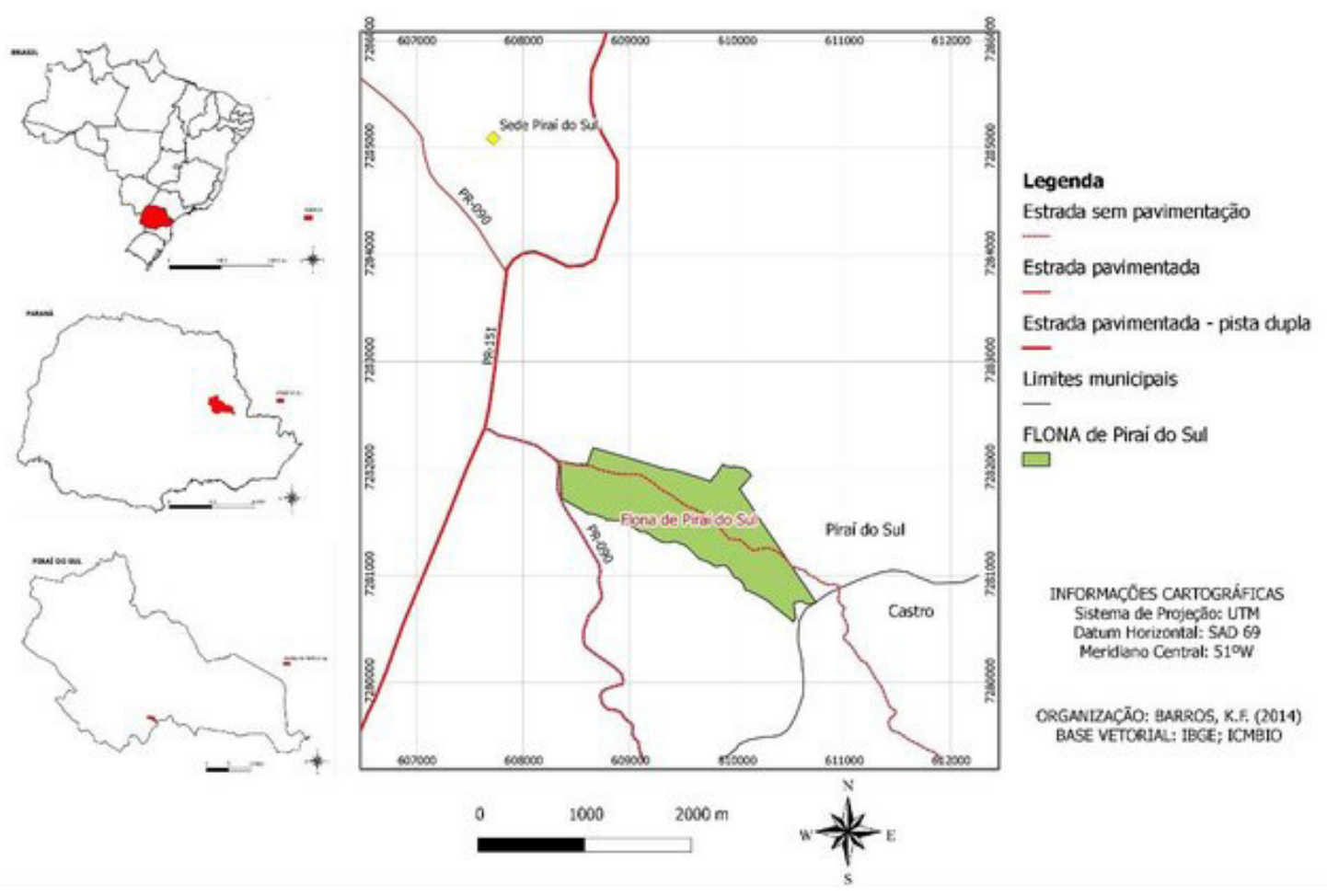

Fonte: Barros (2015).

A FLONA de Piraí do Sul possui uma região de vegetação diversificada, com reflorestamento de Araucárias (Araucaria angustifólia) e outras formações vegetais e a presença de fauna nativa (PINHEIRO; ANTIQUEIRA, 2019). É um importante espaço criado para conservação de recursos naturais que, segundo Moreira e Rocha (2010), são base para o interesse científico, a educação ambiental e o lazer para a comunidade.

A UC possui quatro trilhas ecológicas com diferentes graus de dificuldade, para atender desde crianças da Educação Infantil até 
A contribuição das tecnologias de informação e comunicação em espaços... Lia Maris Orth Ritter Antiqueira•Rubia Freitas Pinheiro• Romeu Miqueias Szimoski

adolescentes (Ensino Fundamental e Médio) e adultos. A Figura 2 ilustra a localização das trilhas na área de estudo.

\section{Procedimentos}

Ao longo das trilhas foram identificadas as principais informações relacionadas aos seus aspectos bióticos e abióticos, aliado a isso, temas relacionados à Educação Ambiental e aos conceitos de Geografia. Foram realizados registros fotográficos e coletadas informações da equipe gestora da UC, além de pesquisa em literatura. Foram produzidas placas de metal (Figura 3), sendo colocadas em lugares estratégicos das trilhas que possuem um código QR Code fornecido pelo software QR Code Generator ${ }^{1}$.

Figura 2 - Mapa de localização das Trilhas de Piraí do Sul

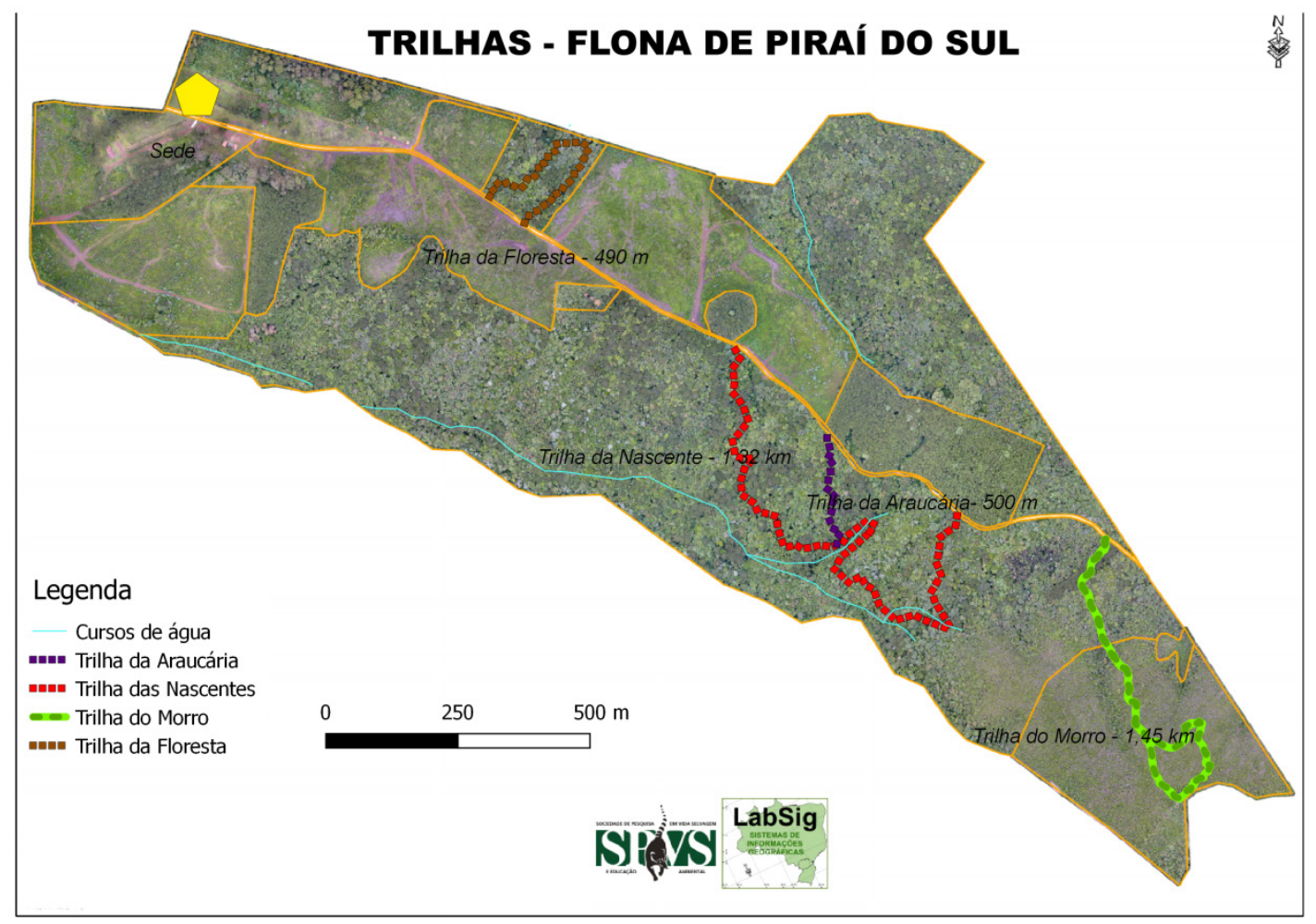

Fonte: Barros (2015).

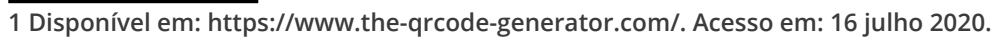


A contribuição das tecnologias de informação e comunicação em espaços... Lia Maris Orth Ritter Antiqueira•Rubia Freitas Pinheiro• Romeu Miqueias Szimoski

O aplicativo tem seu desenvolvimento tanto na programação quanto aparência pelo sistema do APP Inventor $2^{2}$ e o site com as informações preliminares já foi disponibilizado ${ }^{3}$, de modo que ao percorrer a trilha com uso de celular ou tablet, o visitante possa por meio do QR Code ser direcionado para o aplicativo e consulte as informações relevantes sobre o ponto em que está transitando.

As placas foram fixadas em pontos estratégicos desde a entrada da UC, onde se encontra o Centro de Visitantes e a sede do ICMBio, passando pelas trilhas (Figura 3). Ressalta-se que a UC recebe visitas de escolas, colégios, centros municipais de educação infantil, grupos de escoteiros, empresas que realizam atividades ao ar livre, saídas de campo de faculdades e universidades, além das gincanas, atividades de ensino, pesquisa e extensão organizadas pelos próprios gestores e colaboradores da FLONA de Piraí do Sul.

Figura 3 - Modelo da placa para identificação dos pontos nas trilhas da FLONA de Piraí do Sul

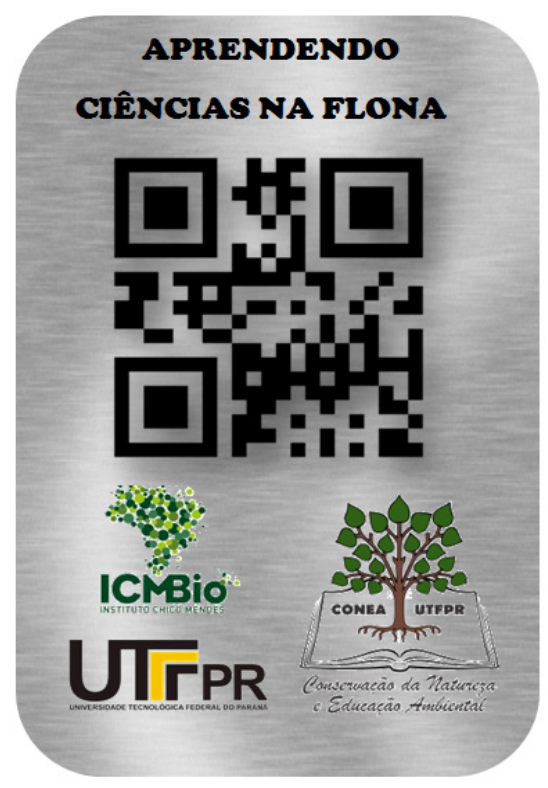

Fonte: autoria própria

$\overline{20}$ MIT App Inventor, também conhecido como App Inventor for Android, é uma aplicação código aberto originalmente criada pela Google, e atualmente mantida pelo Massachusetts Institute of Technology (MIT). Em 6 de dezembro de 2013, o MIT App Inventor 2 foi lançado, renomeando a versão original como "App Inventor Classic".

3 https://sites.google.com/view/ciencianaflona 
A contribuição das tecnologias de informação e comunicação em espaços... Lia Maris Orth Ritter Antiqueira.Rubia Freitas Pinheiro• Romeu Miqueias Szimoski

Pensando em atender todos os usuários das trilhas, principalmente os que não dispunham de equipamentos para acesso ao aplicativo, foi viabilizada a doação de 20 tablets (marca FOSTON) pela Universidade Tecnológica Federal do Paraná (UTFPR), Campus Ponta Grossa-PR para a chefia da UC. Estes equipamentos estavam à disposição da universidade e sem uso específico, sendo repassados por meio de ofício de doação. O aplicativo iFlona (Figura 4) foi instalado nestes tablets e os usuários podem pegar emprestado na sede do ICMBio, devolvendo ao final do passeio. Para os que portam seus próprios dispositivos, basta baixar o aplicativo.

Figura 4 - Tela inicial do aplicativo iFlona, disponível gratuitamente na Google Play Store

\title{
iFlona
}

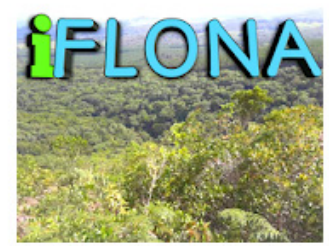

CONEA UTFPR Educação

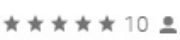

L

(1) Este app é compatível com seu dispositivo.

É possivel compartilhar este item com sua familia

Saiba mais sobre a Biblioteca da familia
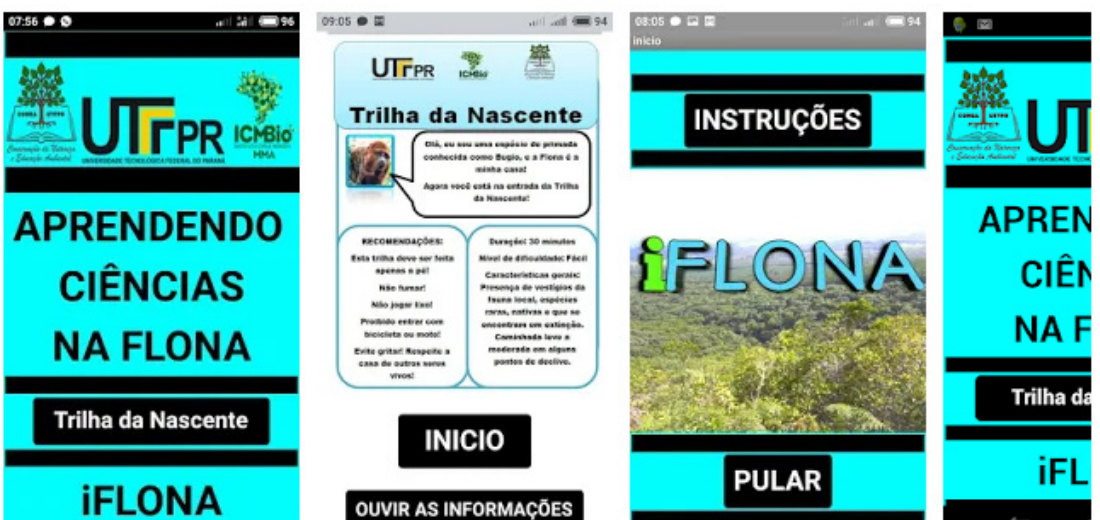

APRENDENDO CIÊNCIAS NA FLONA
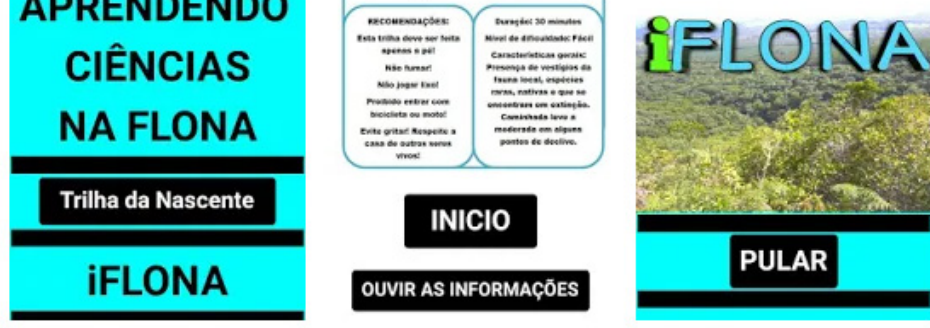

APREN

CIÊI

NAF

Trilha d

iFL

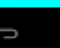

\begin{abstract}
Este aplicativo foi desenvolvido para divulgação de informações sobre os componentes bióticos e abióticos e espaços da Floresta Nacional de Piraí do Sul, Paraná. As informações são obtidas por meio da leitura de códigos QR distribuídos sobre as trilhas da unidade de conservação. Nesta versão, apenas a Trilha da Nascente foi contemplada. As informações são todas científico-educacionais e nenhuma coleta de dados do usuário é realizada durante a aplicação.
\end{abstract}




\section{Resultados preliminares e perspectivas futuras}

Os resultados obtidos até então têm demonstrado que o aplicativo atende às expectativas de captar a atenção dos usuários, tendo acesso rápido (entre 1 e 2 segundos após captação do QRCode a imagem é carregada). Porém, há muitos elementos importantes das trilhas que ainda não foram vinculados ao aplicativo e que precisam ser analisados para implementação. Este trabalho vem sendo realizado paralelamente à estruturação e readequação das trilhas pela equipe do ICMBio e pelos colaboradores voluntários.

Pretende-se validar as impressões dos usuários, especialmente dos professores e alunos do ensino fundamental, por meio de um questionário que aborde suas impressões sobre o uso das TICs nas atividades realizadas nas trilhas, servindo também como subsídio para implementar melhorias constantes. Por enquanto, iFlona pode ser avaliado pelos usuários diretamente na Google PlayStore, por meio de comentários.

Na próxima etapa do trabalho, o aplicativo incluirá os novos elementos das trilhas que vem sendo identificados (espécies raras, endêmicas, fluxo gênico, características do solo e do relevo, recursos hídricos, entre outros). Além disso, pretende-se direcionar os QR Codes diretamente para um site, de forma que o usuário possa escolher o tipo de acesso de sua preferência.

Outra questão a ser implementada via site é a disponibilização de textos, imagens e recursos de ensino para o professor que quiser complementar a experiência posteriormente em sala de aula, sempre focando no aspecto interdisciplinar.

\section{Considerações finais}

Com o aumento significativo da disponibilidade de recursos tecnológicos, as TICs acabam se tornando uma possibilidade de 
A contribuição das tecnologias de informação e comunicação em espaços... Lia Maris Orth Ritter Antiqueira.Rubia Freitas Pinheiro• Romeu Miqueias Szimoski

implementação de mudanças significativas nos processos de ensino e aprendizagem. Quando utilizadas com planejamento, colaboram na leitura, interpretação e conexão das pessoas com o conhecimento.

A inserção das TICs no ensino em espaços não formais tem se mostrado promissora, ao permitir explorar diversas atividades, buscando a sensibilização e a aproximação do ser humano com a natureza, especialmente o público infantil e jovem. Criam-se possibilidades de aprendizado e uma análise crítica sobre a vida no planeta, bem como a importância dos elementos e recursos que fornecem possibilidades de sobrevivência às mais variadas espécies.

Porém, a implementação de recursos tecnológicos, especialmente nos espaços não formais, demanda planejamento prévio e análise de diversas questões. É preciso conhecer o ambiente, selecionar os aspectos a serem abordados e preparar as ferramentas que serão utilizadas. Há custos envolvidos, além das limitações de difusão e acesso, que precisam ser trabalhadas dia a dia.

Cabe ao professor identificar as potencialidades e desafios destes processos e atuar como mediador entre o aluno e o conhecimento, utilizando as TICs como auxílio para formular uma visão instigante dos mais diversos assuntos que abordará.

As experiências com o aplicativo iFlona, mesmo que ainda preliminares, já têm mostrado a gama de possibilidades a serem exploradas e permitido identificar necessidades de melhorias. Uma das questões a ser abordada é a disponibilização de acesso a um site interativo com informações textuais, imagens e roteiros de atividades interdisciplinares. Quanto mais possibilidades de retomada dos conteúdos puderem ser fornecidas, mais significativa terá sido a experiência e a contribuição para professores e alunos que fizeram uso deste recurso. 
A contribuição das tecnologias de informação e comunicação em espaços... Lia Maris Orth Ritter Antiqueira.Rubia Freitas Pinheiro• Romeu Miqueias Szimoski

\section{Agradecimentos}

Aos gestores e funcionários da Floresta Nacional de Piraí do Sul/ICMBio, pela oportunidade de produzir tal trabalho, recebendo a equipe do CONEA com todo o respeito e hospitalidade, especialmente nas figuras da chefe da UC, Elaine Teixeira da Silva, da bióloga Karina Barros e de Arnoldo Felix da Silva e Adriana Woicizack. À UTFPR, pelo apoio financeiro (auxílio TCC, doação de tablets e auxílio financeiro no Edital PROPPG 07/2018).

\section{Referências}

ALMEIDA, M. I. S. DE. A EMERGÊNCIA DA EDUCAÇÃO AMBIENTAL NO CENÁRIO MUNDIAL: EVOLUÇÃO DOS CONCEITOS E CONCEPÇÕES DA EDUCAÇÃO AMBIENTAL. Boletim Goiano de Geografia, GoiÂniA, v. 20, N. 1, p.19-42, 2000. HTTPS://DOI.ORG/10.5216/BGG.V2011.4227

AUGUSTO, K. P. C. M. As TICs na educaÇão do CAmpo: uma ANÁlise da situação do estado do Rio de Janeiro. Orientador: Isabel Cunha, 2014. 363 F. Tese (Doutorado) - Departamento Filosofia, Informação e Comunicação da Faculdade de Letras, Universidade de Coimbra, Portugal, 2014.

BARROS, K. F. DE. Conectividade estrutural e funcional da paisagem da Floresta Nacional de Piraí do Sul e entorno, PR Brasil. Orientador: Rosemeri Segecin Moro, 2015. 131 f. Dissertação (Mestrado) - Programa de Pós-graduação em Geografia, Universidade Estadual de Ponta Grossa, PontA Grossa, 2015.

BIZERRIL, M. X. A.; ANDRADE, F., D. S. A Escola E A CONSERVAÇão do Cerrado: uma análise do Ensino Fundamental do Distrito Federal. Revista Eletrônica do Mestrado em Educação Ambiental, Brasília, v. 10, N. 10, P.19-31, JAN. 2003.

Brasil. Ministério da Educação e do Desporto. Secretaria de Educação Fundamental. Parâmetros curriculares nacionais - terceiro e quarto 
A contribuição das tecnologias de informação e comunicação em espaços... Lia Maris Orth Ritter Antiqueira•Rubia Freitas Pinheiro• Romeu Miqueias Szimoski

Ciclos do ensino fundamental: teMAS tRANSVERSAIS. BRASíliA, DF: MEC/SEF, 1998.

BRASIL. LEI Nº 9.795, de 27 de ABRIL de 1999. DISPÕE SOBRE AS DIRETRIZES para a elaboração da lei. Diário Oficial da República Federativa do Brasil, BRASÍLIA, DF.

BRASIL. LeI No 9.985 de 18 de JULho de 2000. InstituI O Sistema Nacional de Unidades de Conservação da Natureza. Diário Oficial da República Federativa do Brasil, Brasília, DF.

BRASIL. Ministério do Meio Ambiente e Ministério da Educação. Programa Nacional de Educação Ambiental. Brasília: MMA e MEC, 2005.

BRASil. Ministério da Educação. Secretaria de Educação Básica. Conselho Nacional de Educação. Conselho Nacional de Secretários de Educação. União Nacional dos Dirigentes Municipais de Educação. Base Nacional Comum Curricular (BNCC). Brasília: MEC; SEB; DICEl, 2017.

BRASil. Ministério da Educação. Secretaria de Educação Básica. Conselho Nacional de Educação. Conselho Nacional de Secretários de Educação. União Nacional dos Dirigentes Municipais de Educação. Base Nacional Comum Curricular (BNCC). Brasília: MEC; SEB; DICEI, 2018.

COSTA, N. M. C. DA; COSTA, V. C. DA; MELLO, F. A. P. A escola e suA LIGAÇÃO COM AS UNIDADES DE CONSERVAÇÃO: ANÁLISE DO CONHECIMENTO E PERCEPÇÃo dOS ALUNOS SOBRE O MEIO AMBIENTE. IN: Simpósıo NaCional SObRe GEOGRAFIA, PERCEPÇÃo E COGNIÇÃo do MEIO AMBIENTE, I. LONDRINA, UEL, 2005.

ELIAS, M. Del C. A atualidade da proposta Freinet: interdisciplinar E alfabetização. In: EliAS, M. del C. Pedagogia Freinet: teoria e prátiCA. Campinas: Papirus, 1996. P. 51-61.

FReinet, Célestin. As técnicas Freinet da escola moderna. 4. ed. Lisboa: ESTAMPA, 1975. 170 P.

JACOBUCCI, D. F. C. CONTRIBUiçÕES dOS ESPAÇOS NÃO FORMaIS DE EDUCAÇÃO para a Formação da CUltura CIentífica. Em Extensão, Uberlândia, v. 7, N. 7, P.55-66, 2008. 
A contribuição das tecnologias de informação e comunicação em espaços... Lia Maris Orth Ritter Antiqueira•Rubia Freitas Pinheiro• Romeu Miqueias Szimoski

KAYSER, E. E.; MONTES, Guilherme Augusto. Aprendizagem com o uso da tecnologia no ensino da Biologia. In: Congresso de ensino, pesquisa e extensão da ueg, 4., 2017, Pirenópolis. Anais...PIRenópolis: Cepe, 2017. P. 1-10. (v. 4).

MOREIRA, J. C.; ROCHA, C. H. UnidAdes de Conservação nOS Campos Gerais. In: MELO, M. S. de; MORO, R. S.; GUIMARÃES, G. B. Patrimônio Natural dos Campos Gerais do Paraná. Ponta Grossa: EDITORA UEPG, 2010.

PINHEIRO, R. F.; ANTIQUEIRA, L. M. O. R. CiÊnCIA NA Flona: IMPLEMENtação de QR Codes nas trilhas ecológicas da Floresta Nacional de Piraí do Sul PR. In: Congresso de ecologia, 14., 2019, SÃo Lourenço. Anais... SÃo Lourenço: SOCIEDAde de ECOlogIA do BRASIL, 2019. P. 1-2.

PINHEIRO, R.F.; ANTIQUEIRA, L.M.O.R. SZIMOSKI, R.M. IFLONA. 2019. DISPONÍVEL EM:HTTPS://PLAY.GOOGLE.COM/STORE/APPS/DETAILS?ID=APPINVENTOR.AI_RUBIAPINHEIROGIRL.IFLONA\&HL=PT_BR ACESSO EM: 16 JUL. 2020.

PIVELLI, S. R. P. ANÁlise do POTENCIAL PedAgógico de ESPAÇOS NÃo ForMAIS DE ENSINO PARA O DESENVOLVIMENTO DA TEMÁTICA DA BIODIVERSIDADE e sua conservação. Orientador: Clarice Sumı Kawasaki, 2006. 165 f. Dissertação (Mestrado) - Universidade de São Paulo, São Paulo, 2006. RIBAS, A. S.; SILVA, S. de C. R. dA; GALVÃO, J. R. Telefone Celular como RECURSO didÁtICO NO ENSINO de FísICA. CURITIBA: EdITORA UTFPR, 2015. 111 P.

RODRIGUES, G. S. de S. C.; COLESANTI, M. T. De M. Materiais didÁticos para EducaçÃo Ambiental em UnidAdes de ConservaçÃo: AS POSSIBILIDADES DE uso da hipermídia. Boletim Goiano de Geografia, v. 35, N. 2, p. 289-304, 2015. HTTPS://DOI.ORG/10.5216/BGG.V35I2.37432

SAMPAIO, R. M. W. A AULA-PASSEIO TRANSFORMANDO-SE EM AULA DE DESCobertas. In: Elias, Marisa del Cioppo. Pedagogia Freinet: teoria e prátiCA. CAMPInAS: PAPIRUS, 1996. P. 179-195.

SANTANA, M. A. B. TICs e EducaçÃo: o blog em Sala de aula. Orientador: João Tadeu WeCk. 2015. 62 f. Monografia (Especialização) - Curso de 
A contribuição das tecnologias de informação e comunicação em espaços... Lia Maris Orth Ritter Antiqueira•Rubia Freitas Pinheiro• Romeu Miqueias Szimoski

Pedagogia, Universidade Federal do Rio Grande do Norte Centro de EducaçÃo, NATAL, 2015.

SHIMADA, M. S.; TERÁN, A. F. A RELEVÂNCIA DOS ESPAÇOS NÃO FORMAIS PARA O ENSINO DE CIÊNCIAS IN: ENCONTRO INTERNACIONAL DE ENSINO E PESQUISA EM CIÊNCIAS NA AMAZÔNIA, 4, 2014, TABATINGA. ANAis... Tabatinga: Cestb/UEA, 2014.

SOUZA, B. de. Mobile Learning: Educação e tecnologia na palma da mão. Cariacica: Mobile LearningPedia, 2012.

VASCONCELOS, C. A. DE; OLIVEIRA, E. V. TIC NO ENSINO E NA FORMAÇÃO DE PROFESSORES: REFLEXÕES A PARTIR DA PRÁtICA DOCENTE. REVISTA

Brasileira de Ensino Superior, v. 3, N. 1, P.112-132. hTtP://dX.DOI. ORG/10.18256/2447-3944/REBES.V7N1P112-132.

VIEIRA, V.; BIANCONI, M.L.; DIAS, M. ESPAÇOS NÃO FORMAIS DE ENSINO E O currí́culo de Ciências. Ciência e Cultura, v. 57, n. 4, p. 21-23, 2005.

\section{Declaração de contribuição individual}

Declaramos que todos os autores ofereceram substanciais contribuições científicas e intelectuais ao estudo. As tarefas de concepção e design do estudo, preparação e redação do manuscrito, bem como, revisão crítica foram desenvolvidas em grupo. A primeira autora (Lia Maris Orth Ritter Antiqueira) ficou especialmente responsável pelo desenvolvimento teórico-conceitual e orientação geral de todas as tarefas além da comunicação com a revista. A segunda autora (Rubia Freitas Pinheiro) adquiriu os dados em campo, interpretou, analisou, implementou o aplicativo e coletou os resultados para análise. O terceiro autor (Romeu Miqueias Szmoski) contribuiu igualmente com os procedimentos técnicos relacionados ao aplicativo e com a escrita

Lia Maris Orth Ritter Antiqueira - Possui graduação em Ciências Biológicas pela Universidade Estadual de Ponta Grossa, mestrado em Gestão do Território pela mesma Universidade e Doutorado em Ciências: Conservação de Ecossistemas Florestais pela Universidade de São Paulo. Atualmente é docente da Universidade Tecnológica Federal do Paraná, Câmpus Ponta Grossa.

ORCID: https:/orcid.org/0000-0001-8453-0751

Rubia Freitas Pinheiro - Licenciada em Ciências Naturais. Mestranda em Ensino de Ciências e Tecnologia na Universidade Tecnológica Federal do Paraná, Câmpus Ponta Grossa. ORCID: https://orcid.org/0000-0002-0510-8956

Romeu Miqueias Szmoski - Possui graduação em física pela Universidade Estadual do CentroOeste, mestrado em ciências pela Universidade Estadual de Ponta Grossa e Doutorado em Ciências: Física pela mesma Universidade. Atualmente é docente da Universidade Tecnológica Federal do Paraná, Câmpus Ponta Grossa. ORCID: https://orcid.org/0000-0002-0968-7158

Recebido para publicação em 18 de maio de 2020

Aceito para publicação em 29 de junho de 2020

Publicado em 7 de agosto de 2020 